\title{
壓延加工せる $\mathrm{Al}$ 單結晶板の二次再結晶について (第 3 報 $)^{*}$
}

\author{
大 河 原 謙二 郎**
}

Kenjiro Okawara: Study on Secondary Recrystallization of Cold-rolled Aluminium in Single Crystal (3rd Report). Single crystals in nearly (111), (100) and (110) orientation were cold-rolled by 50,75 and $90 \%$ and were annealed to produce both primary and secondary recrystallization structures. A detailed study of the change in grain size and in orientation was made using light figure, etch pit and X-ray method. When (111) specimens were coldrolled by $75 \%$ and annealed for $60 \mathrm{~min}$ at $300^{\circ}$, the primary. recrystallization produced a finegrained structure with a high percentage of primaries in one prefered orientation, and when annealed for $2 \mathrm{hrs}$ more at $600^{\circ}$, relatively large primary grains in orientations deviating markedly from the primary recrystallization texture grew into secondary grains having specific preferred orientations. On the other hand, when (111) specimens were annealed for $2 \mathrm{hrs}$ at $600^{\circ}$ directly after being cold-rolled by $75 \%$, the secondary of the same oriientation as the matrix were very often found and this phenomenon seems to mean that low-energy polygonized grain grow rapidly into secondary at the expense of the adjacent strained grains. Therefore, not only the grain boundary energy but also the internal strain energy seems to play an important role for the secondary recrystallization.

\{Received November 24, 1955\}

\section{I. 緒}

前報(1)(2)に沏いてA1 單結晶板を $75 \%$ 壓延後 $600^{\circ} \times$ $2 \mathrm{hr}$ 燒鈍せる際, 著しい粗大化現垠を呈せる (111) 近傍方 位試料と, 全くか〉る現象を呈しない (100) 打よび (110) 近傍方位試料の㗨延過程並びに燒鈍過程に拈ける諸性質變 化を調べ，それらの結果について，弡表した，その結果， X-ray photo.によれば (111) 近傍方位試料のみは, $300^{\circ}$

** 東海金屬袾式會缡:

* 1955 年 10 月本會金澤大會に發表

(1) 大河原，本誌，19(1955), 555 .

(2) 大河原，本誌，19(1955), 558.
憢鈍による一次再結晶後も極めて鮮銳な聚合組織を呈して いることがらから゙われた。

これは, 粗大化現象と關連して, 注目に值する現象であ る.著者は引續きこの現象の解明について研究を續けてい るが，今回は上記代表的三方位 (111)，(100)，(110)近傍 方位試料の嬮延, 再結晶過程における方位並びに組織の變 化について研究した結果を報告する.

\section{II. 宣 駽 試 料}

試料としては $99.996 \%$ 純度の $\mathrm{A} 1$ を用い, 再結晶法に より作つた單結昆板より所要の方位のものを切出した.

その化學分析の結果は Table 1 の如くである. 
Table 1 Results of chemical analysis of metal used.

\begin{tabular}{l|l|l|l|l|l|l|l|l|l|}
\hline \hline Impurity & $\mathrm{Al}$ & $\mathrm{Fe}$ & $\mathrm{Si}$ & $\mathrm{Cu}$ & $\mathrm{Mg}$ & $\mathrm{Mr}$ & $\mathrm{Ti}$ \\
\hline
\end{tabular}

Aluminium $99.996|0.001| 0.0020 .001$ none $\mid$ trace $\mid$ none

\section{III. 菑 䴋 結 果}

賔簽に使用せる試料の結晶方位は，Fig.1 の標蕉ステレ オ三角形內に示す如くである。

\section{1. 铎延聚合組織}

(111)，(100)，怙よび (110) 近傍各方位の單結昆板を50， 75，90，各％遒延せる際の平均結晶方位を光像法 並びに 蝕管法により調べた結果は, Fig. 2 括よび Photo. 1 に示 寸如くで，(111)，(100)，(110) 三だ位の試料ではその 壓延聚合組織に明瞭な相違が見られ，壓延度による結晶方 位變化は，まず壓延面に本行な面方位は，(111) group 試 料では壓延度の墂すに從つて(111) より (5910) を經て (156) に向い，75\% Red を超えると反轉して (123) 方 位へ近すいて行くよらであり，(100) group 試料では,

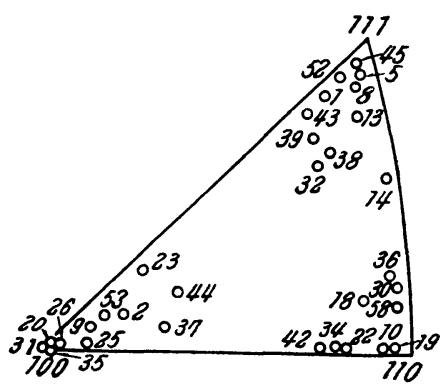

Orientation of the plane parallel to the rolling plane.

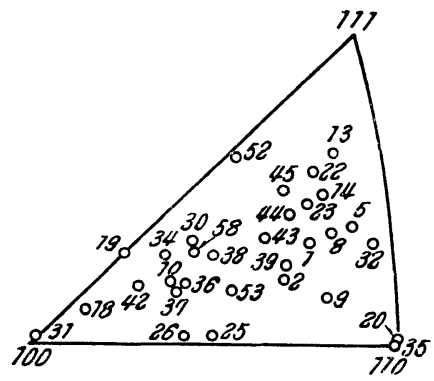

Orientation of the direction parallel to the rolling direction.

Fig. 1 Orientation of specimens used.

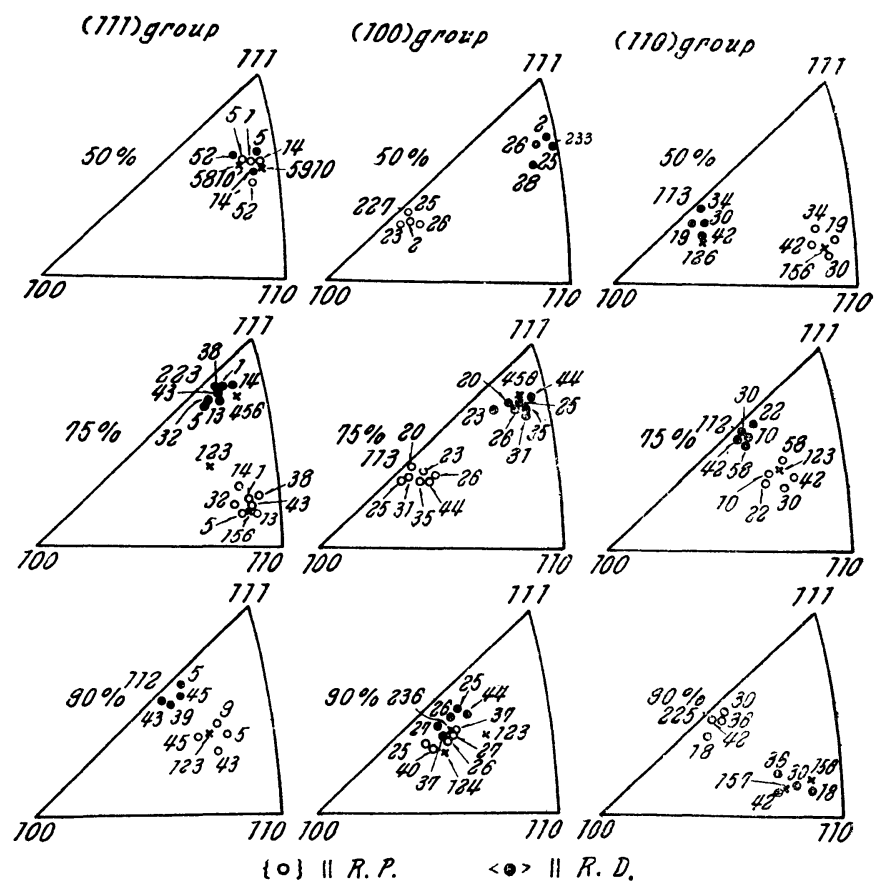

Fig. 2 Average orientation of cold-rolled texture.
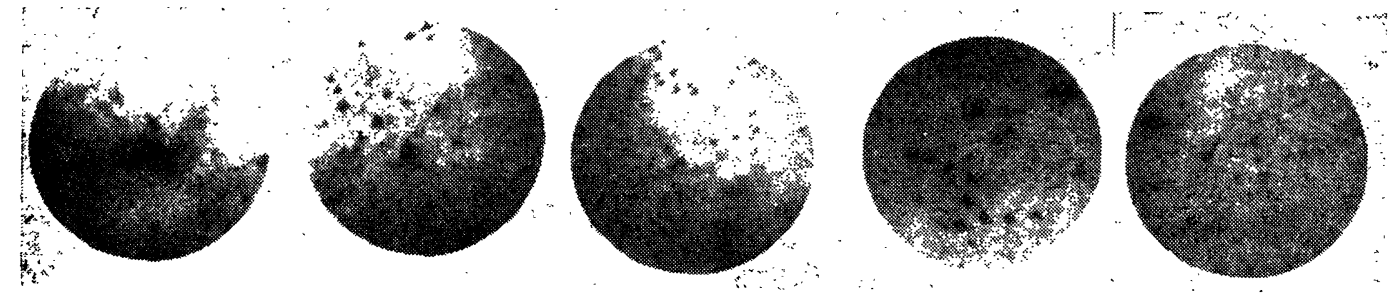

R. D. $\rightarrow$

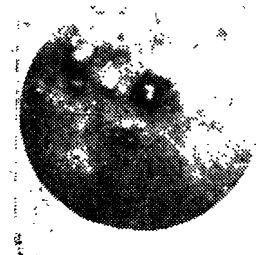

single crystal

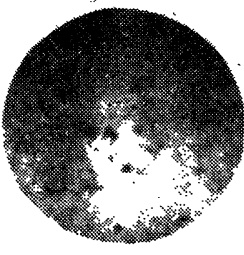

$30 \%$ redu.

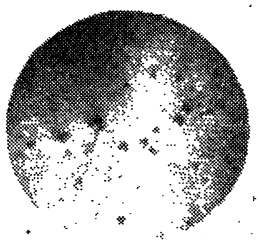

$50 \%$ redu.

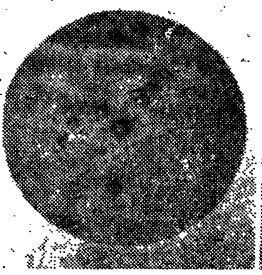

$75 \%$ redu.

Upper: Specimen No. 5 (111) Under: No. 25 (100)

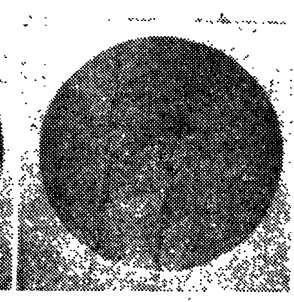

$90 \%$ redu.

$(\times 100 \times 1 / 2)$

Photo. 1 Change of the shape of etch pits due to cold rolling. 
(100)より（113）を經て前者と同じく (123) 方向一向 い, 90\% Red で (236) 方位へ達している. また（110)
(111) Specimen

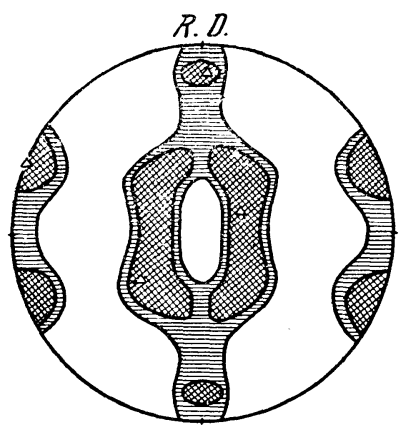

$\Delta(756)(101115)$
(100) Specimen

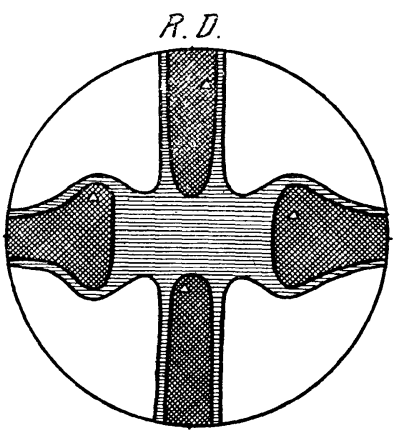

$\Delta(713)(456)$
Fig. 3 (111) Pole figure for the texture of $75 \%$ rolled Al single crystal.

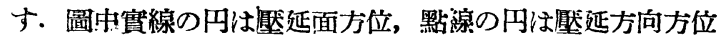
を表わし，かつその集合度の大きさに憵じて，實線の内の み大きさを變えて示した.これら main-component の方立はいずれも，もとの結晶格厅に對して [111] 軸の周りに $20 \sim 40^{\circ}$ 回轉した關係にある.な招圖に は各 main-component の大凡の集合点を面程\%で 示したが，これによると $75 \%$ 㗨延せる(111)group 試料の一次再結晶組織のみ住, (156) 型方位粒于の 集合度が $96 \%$ に执よで極めて鮮銳な組織を示して いる.これは特に注目に值する現触であり，また前 報(2)X-ray photo. の結果と極めてよく一致するも のである.

\section{3. 二次再結晶聚合組織 (粗大化柆子の方位)}

(111) group 試料を $75 \%$ 㙠逐後 $600^{\circ} \times 2 \mathrm{hr}$ 燒鈍 して, 粗大化した粒于 (secondary) の方位を光像沠

group 試料では (156)，(1:3) を經て(225) 方位へと變化している. 一方髡延方向の方 位は，單結晶狀態の堅延方向の方位にあま り關係なく, (111) group では $<5910>\rightarrow$ $<456>-<223>\rightarrow<223>$, (100) group は $<233>\rightarrow<456>\rightarrow<236>$, (110) group では $<126>-<113>\rightarrow<112>\rightarrow<157>$ と 變化している．さらに光像洗並びに蝕像沠に よる聚合組織の決定を check する意味で, (111) 怙よび (100) group 75\%厴延試料 を，X-ray により調べたところ，Fig. 3 に (111) 極點訚形で示した吝く，前記の結果と よく一致して括り，これらはこれまでの研究 結果 ${ }^{(3)}$-(13) による多結晶 $\mathrm{Al}$ の壓延聚合組織 のそれぞれ一部分を形成していると考えてよ いと思われる.

\section{2. 一次再結晶聚合組織}

次に上記 50, 75, 용 各\% 誆延せる試料を $300^{\circ} \times 1 \mathrm{hr}$ 燒鈍せる際に得られた一次再結晶 組織の main-component の方位を, 蝕像法 により統計的に決定した結果を Fig.4に示

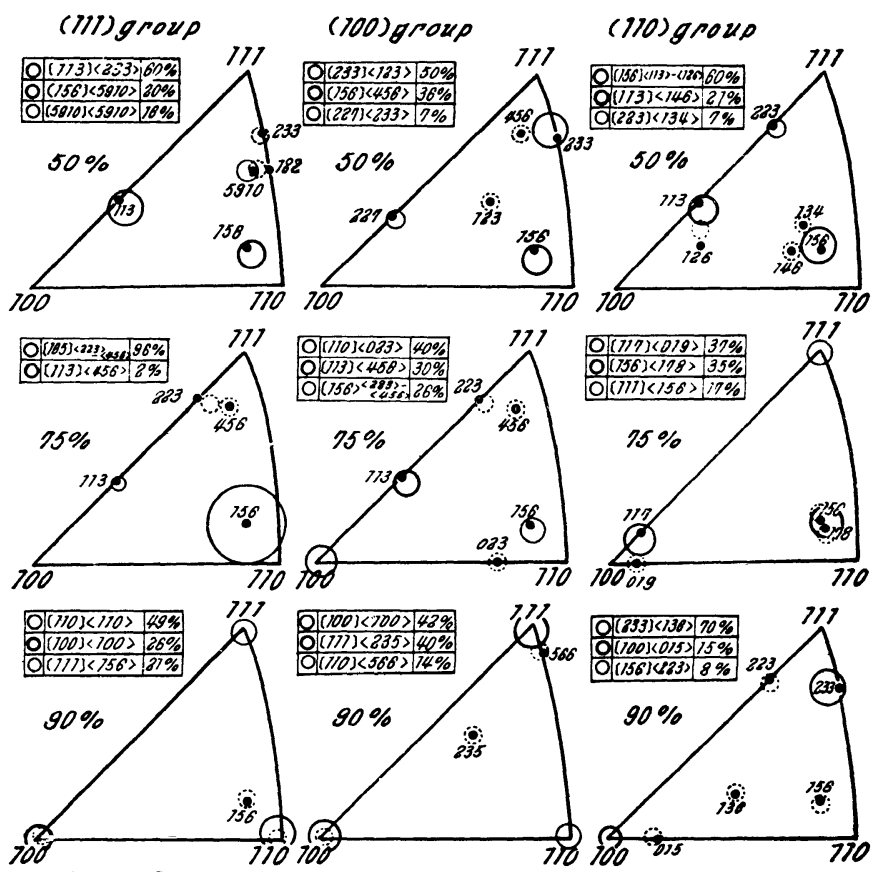

Fig. 4 Orientation of main components of primary texture. (Annealed $1 \mathrm{hr}$ at $300^{\circ}$ after various \% cold rolled)

(3) Owen, E. A. \& G.D. Preston, Proc. Phys. London., 38(1926), 132.

(4) Vargha, G. V. u.G. Wassermann, Metallwirtsch., 12(1933), 511.

(5) Göler, Frhr V.u. G.Sachs, Z. Phys., 56(19:29), 477.

(6) Thewls, J. Phil. Mag., (7) 10(1930), 953.

(7) Burgers, W. G. u. J. L. Snock, Z. Metallk. , 27 (1935), 158.

(8) Göler, Frhr V.u. G. Sachs, Z. Phys., 41(1927), 873.

(9) Barrett, Structure of Metals.

(10) 䟽田, 小池, 輕金屬, 5(1952), 35.

(11) H. Hu \& P.A. Beck, Trans. AIME, 188(1950), 1214.

(12) 五弓，阿部，本誌， 16(1952), 534.

(13) C. G. Dunn, Acta Met., 2(1954), 386.

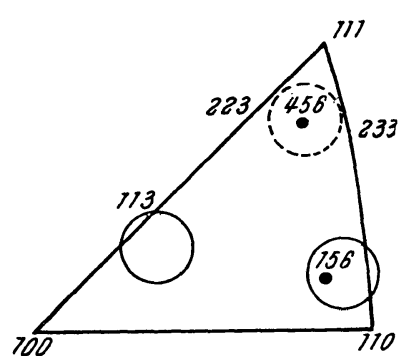

(O\}\|R.P. ¿>\|R.D.

Fig. 5 Orientations of main components of secondary texture. (Anneald $2 \mathrm{hr}$ at $600^{\circ}$ after $75 \%$ cold-rolled)
により測定した結果を

Fig.5 に示す.これに よると大略 secondary の方位は $\{156\}<456>$ 扣よび $\{113\}<456>$ 型方位によつて代表 せられるが，この二つ の型の方泣は，その一 次再結晶中にすでに存 在して扣り, 特に前者 はその main-component である. すな 
わち, secondary の方位は primary の䓞位と極めて密接 な關係にあることが判る。

一方 (100) group 試料を $75 \%$ 厭延後 $600^{\circ} \times 2 \mathrm{hr}$ 衫鈍 せるところ, 前記の詃く secondary の弡生は見られなかつ たが, その組織は㗨延組織からの殘留方位粒于が消減して 〔111]㬍回轉關係方位の粒于の生長が見られ,特に立方體 方位の增加が顯著に觀察され，その集合度は約 $60 \%$ に澾 した.

\section{Primary の發生および生長の過程}

以上の實驗より粗大化粒于の方位が, primary の方位と 極めて密接な關係のあることが知られたので，この間の關 係をさらに詳しく調べるため (111) 怙よび (100) 近傍方位 試料を， $75 \%$ 壓延後 $300^{\circ}$ で $15 \mathrm{~min}$ 扔よび $60 \mathrm{~min}$, 續 Wて $450^{\circ}$ で $1 \mathrm{hr}$, さらに $600^{\circ}$ で $2 \mathrm{hr}$ 燒鈍して primary の磁生並びにその成長過程を肉眼並びに蝕鱼法により調べ た. 實騟結果の一例をPhoto. 2 をに示す.

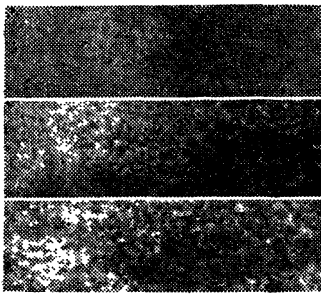

(100) (113) (156)typeprimary
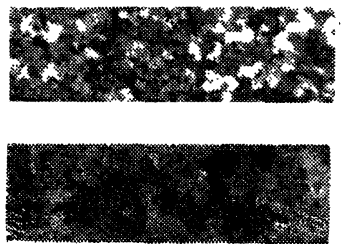

No. 9 (100) (a)

(b)

(c)

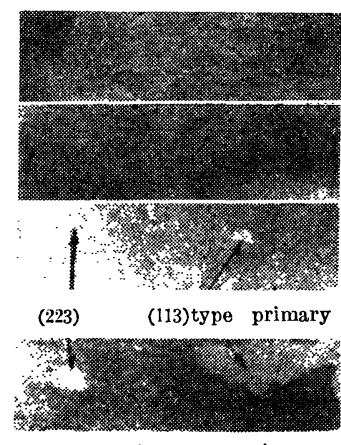

(223) (113)type primary

(e)

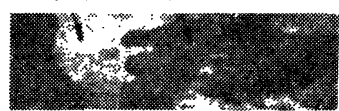

No. 8 (111) (a) as $75 \%$ rolled

(b) after $15 \mathrm{~min}$ at $300^{\circ}$.

(c) after additional $60 \mathrm{~min}$ at $300^{\circ}$.

(d) after additional $60 \mathrm{~min}$ at $450^{\circ}$.

(e) after additional $2 \mathrm{hr}$ at $600^{\circ}$.

Photo. 2 Changes in the grain structure produced by annealing.

これによると，末ず (111) 近傍方位試料では, $300^{\circ} \times 15$ min 燒鈍まではその再結晶組織は壓延組織の殘留によつ て形成され，極めて微細な粒于の集合狀態を呈しているが， $30{ }^{\circ} \times 60 \mathrm{~min}$ 燒鈍によつて試料の 2 ケ所に matrix 粒子よ り稍く成長して大きくなつた (113) 型, 並びに (223)型方位 粒子が現九，さらに $450^{\circ} \times 60 \mathrm{~min}$ 燒鈍によつてこれらの 方位粒于は大きく成長し, matrix 中にあつて傑运してく る.

これをさらに $600^{\circ} \times 2 \mathrm{hr}$ 袒鈍すると，Photo. $2(\mathrm{e})$ に 示寸如く (113), (223) 型方位の secondary 臂生が見られ た.

このうち, $(223)<678>$ 型方位 secondary の出現に關 しては，唇延後值ちに $600^{\circ}$ 燒鈍せる際にはあまり見られ なかつた現象で,これは高溫で燒鈍する前, 低溫度にて長
時、淐燒鈍せるため，比較的正常な變化，すなわち主として 綕晶粒相互間の方位差に基因寸る grain growth か起つ た繥果生じたものではないかと考えられる。

一竕 (100) 近傍方位試料では寸でに $300^{\circ} \times 15 \mathrm{~min}$ 燒鈍 によつて, (100), (113), (156) 型炎の他, 分散方位の再結晶 粒子が㗶生混在しているのが見られ， $300^{\circ} \times 60 \mathrm{~min}$ 燒鈍で

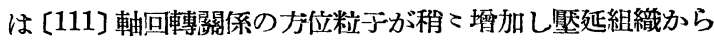
の殘留方位粒丁が減少しているのが見られたが， $450^{\circ} \times 60$ $\min$ 燒鈍に招いては, 各方位粒于は比較的一樣に揃つて大 きくなり，600 $\times 2 \mathrm{hr}$ 燒鈍では前記の如くさらに立方體方 位粒于の成長が見られ，その增加が㙷著に觀察された。

以上 (111), (100), 兩方位近傍試料の primary の發生 並びにその成長過程に执いて，特に兩者の相違紫として顯 著な現象は, primary texture が前者に拉いては極めて微 細陂でかつ，鮮銳な組織であるに反し，後者に执いては粒子 が一樣に揃つて大きく，かつ比較的多數の方位粒子が殆ん ど同時に發生していることである．前者の如き鮮銳な組織 中に (113) 或いは (223) 型方位の如く matrixに對し [111] 軸20４0 回轉の方位關係を有する粒子が weakな component として墢生し, かつ matrix 粒于に對して際 立つて大きな粒お゙となつているとき，この種方位粒子が高 溫に㨟いて燒鈍されたとき secondary 一成長することは 容易に期待できるのであつて，このことは Fe-Si 單結晶を 使用しての C. G. Dunn ${ }^{(14)(15)}$ の結果とよく一致するので ありこれむやはり oriented nucleation growth selectivity theoryによつて說明されるのではないかと考える. しかし一方 matrix と同じ方位の (156) 型方位 secondary の發生についてはどう考えるべきであろうか，もつとも簡 單な考え方としてすでに低罝度に㨟いて，polygonization より生じた低ェネルギーの核が，溫度の急上昇と共に周園 の deformed material を喰つて成長, 一氣に secondary まで進行したとする考え方がある.

すなわちこの場合かつる方位のsecondary 發生の要因と して, 再結晶粒成長速度の巽方性とか粒界エネルギーとか を擧げるのみならず, moving force として歪ェネルギー も考慮に入れた方がよいのではないか, と考えるのである.

\section{IV. 總括}

以上總括すると，まず (111), (100), (110) 近傍方位單

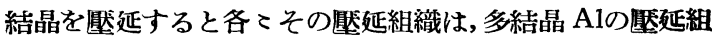
織のそれぞれ一部分に相當する如き特翼の方位 textureを とり，さらにこれを燒鈍すると matrix に對し大體 [111] 軸 $20 \sim 40^{\circ}$ 回轉關係にある方位の再結晶粒テが發生する が，75\% 厭延後 $300^{\circ}$ にて憢鈍せる (111) 近傍方位試料 のみは殆んど壓延組織そのまつの極めて鮮銳なかつ微細糘 の組織を呈し，これをさらに $600^{\circ} \times 2 \mathrm{hr}$ 燒鈍すると，こ の鮮銳な組織中にあつて matrix に對し [111]軸 $20 \sim 40^{\circ}$ 回轉の方位關係にあり,かつmatrix の粒ごに較べ比較的大

(14) C. G. Dunn, Acta Met., 1(1953), 163.

(15) C. G. Dunn, Acta Met., 2(1954), 173 
きな粒子に成長している (113) および (223) 型方位の粒子 が, matrix を喰つて成長を續け secondary 一と發展する. 一方 $75 \%$ 遡延後值ちに $600^{\circ} \times 2 \mathrm{hr}$ 憢鈍せる (111) 近傍 方位試料では matrix と同じ方位の secondary の發生が 多く, これは polygonization から一氣に secondary ま で成長したものと考えられる. いずれにしても早期に形成
された primary が, matrix または他の方位 primary を 喰つて成長し, secondary になるよらであるが, この moving force としては粒界エネルギーのほかに䨤エネルギー も考慮に入れなければならない。

終のに本研究逐行に際し, 終始御指導御鞭韄を賜つた東 京工大山田敎授に厚く感謝の意を表すると共に, 實驗に際 し熱心に協力された柴田君並に 井田倉君に深謝する. 